\title{
Orbital Penetrating Injury by Bamboo-Stick, Mimicking Air in Computed Tomography: A Case Study
}

\author{
Michael Pesis ${ }^{1 *}$, Navot Givol',3, Anatoliy llgiyaev ${ }^{3}$ and Ronit Yagev ${ }^{2}$ \\ ${ }^{1}$ Unit of Oral and Maxillofacial Surgery, Soroka University Medical Center, Beer-Sheva, Israel \\ ${ }^{2}$ Department of Ophthalmology, Soroka University Medical Center, Beer-Sheva, Israel
}

${ }^{3}$ Faculty of Health Sciences, Goldman Medical School, Ben Gurion University, Beer Sheva, Israel

*Corresponding author: Michael Pesis, Unit of Oral and Maxillofacial Surgery, Soroka University Medical Center, Rager Boulevard, PO Box 151, Beer-Sheva 84101, Israel, Tel: 972-54-4314364

\begin{abstract}
Introduction: Orbital penetration injuries by an organic foreign body are relatively rare. It is difficult to detect such foreign bodies by computed tomography (CT) scan. Penetrating injuries through the skin can cause serious orbital complications. This report presents the first case of an intra-orbital penetrating injury caused by a bamboo.

Patients: A case report of a penetrating foreign wooden body that was not identified as such on physical examination but was demonstrated on CT scan. A 25-year-old man arrived sedated to the emergency room (ER). On physical examination, a wooden foreign body was observed on the right side of the upper lip. On CT scan, an air mimicking cylindrical foreign body was noticed. 3D reconstruction demonstrated a cylinder-shaped object penetrating into the orbit, breaking the orbital floor, deflecting the globe cranially and penetrating the apex to the middle cranial fossa without tearing the dura. The object was surgically removed intact. It was identified as a $9 \mathrm{~cm}$ long bamboo stick.

Discussion: Various foreign bodies in the orbit have been described in the literature. They can gain access into the intracranial cavity and can lead to blindness and even death. Organic materials are not well detected by plain radiography. A linear configuration should raise suspicion. In our patient, the foreign body was revealed to be a $9 \mathrm{~cm}$ bamboo stick. High-density 3-dimensional CT examination provided excellent images of the linear configuration mimicking air. Treatments are surgical removal, control of hemorrhage and repair of damage. Broad-spectrum antibiotic prophylaxis and tetanus immunization must be initiated immediately.

Conclusion: This report presents an unusual injury without external signs of orbital penetration. It illustrates the need for meticulous physical examination with correlation to radio graphical findings, especially in cases of outdoor injuries. Awareness of organic objects masquerading as air in CT scans is crucial.
\end{abstract}

\section{Keywords}

Bamboo-stick, Orbital penetrating injury, Injuries to the eye, Wooden projectiles, Mimicking air

\section{Introduction}

Injuries to the eye and orbit caused by foreign bodies can be hazardous to vision and ocular motility [1-3]. They are relatively rare and constitute only $0.4 \%$ of all head injuries $[4,5]$. However, these penetrating injuries can result in serious orbital complications [3-5]. Injuries caused by garden canes, chopsticks and wooden or metallic projectiles are rarely reported but may result in retained orbital or orbito-cranial foreign bodies [6-10]. The external entry wound may be apparently minor and the retained wooden foreign bodies may be difficult to detect radiologically [7,11-17]. One of the complications of penetrating orbital trauma is blindness. This is due to fracture of the lesser wing of the sphenoid bone. Orbital apex syndrome secondary to subdural hematoma of the optic nerve sheath has also been reported $[18,19]$. Orbital complications can be directly related to the injury as muscle entrapment, hematoma, or infection. Further, problems related to surgical access or post-surgery complications such as volume discrepancies may occur [20]. Concomitant transorbital penetrating injuries can causes cerebral injuries which may result in blindness, hemorrhagic conditions, brain stem injuries, cerebrovascular injuries, pneumocephalus, purulent inflammations, and various infections [21]. Early diagnosis and

Citation: Pesis M, Givol N, Ilgiyaev A, Yagev R (2020) Orbital Penetrating Injury by Bamboo-Stick, Mimicking Air in Computed Tomography: A Case Study. Trauma Cases Rev 6:081. doi.org/10.23937/24695777/1510081

Accepted: March 12, 2020: Published: March 14, 2020

Copyright: (c) 2020 Pesis M, et al. This is an open-access article distributed under the terms of the Creative Commons Attribution License, which permits unrestricted use, distribution, and reproduction in any medium, provided the original author and source are credited. 


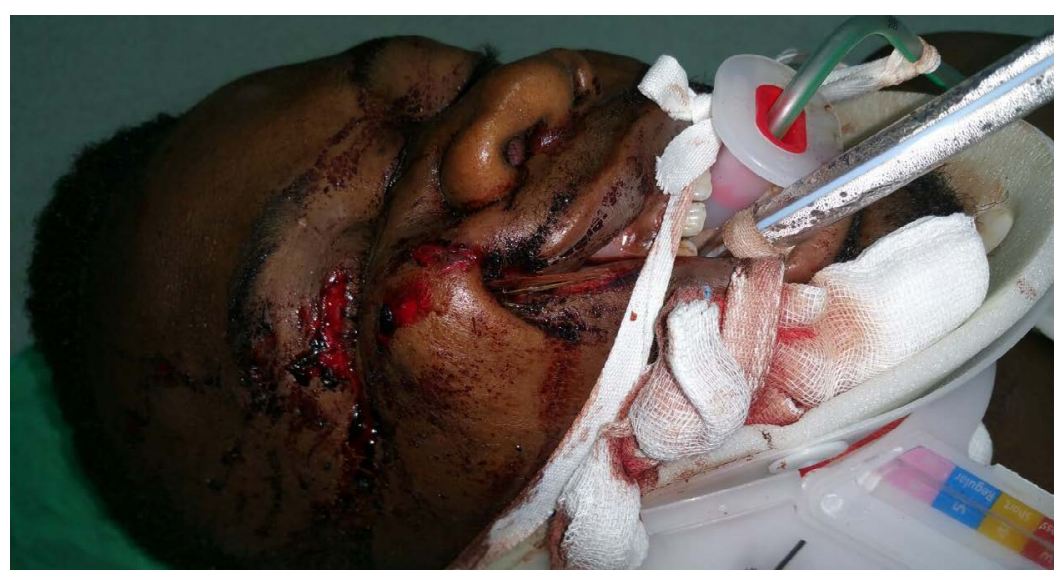

Figure 1: A $1.5 \mathrm{~cm}$ wooden foreign body protruding from the upper lip.

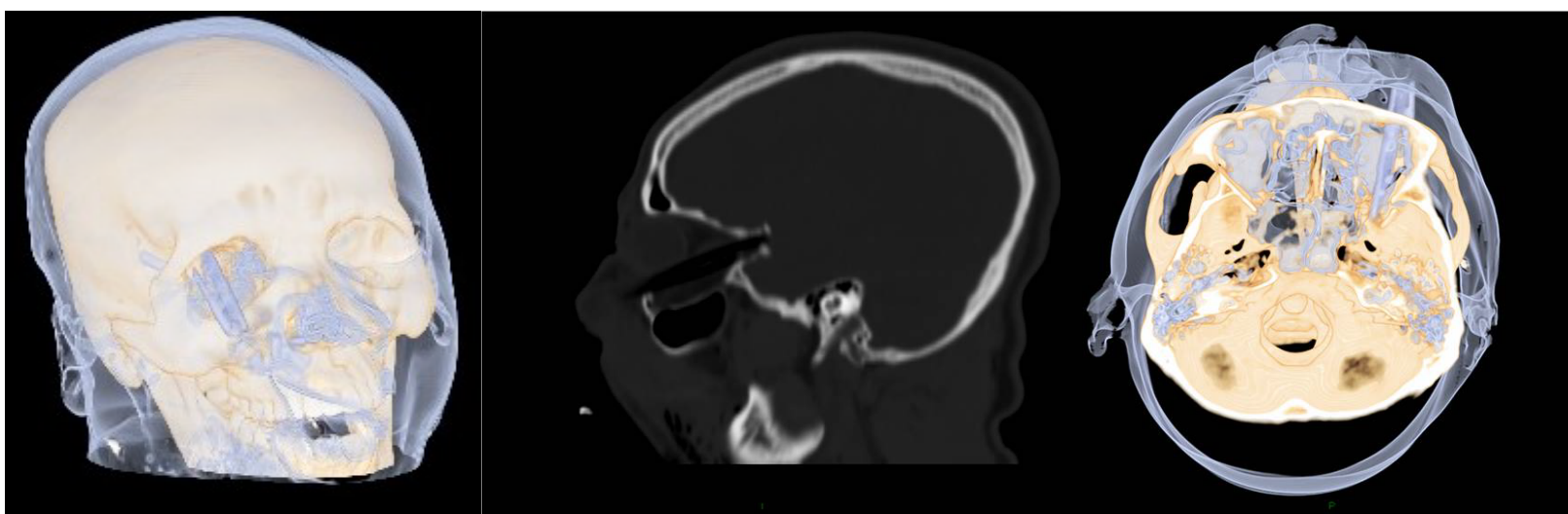

A

B

C

Figures 2: (A, B, C) 3D CT scan demonstrating a foreign body mimicking air in the orbit, deflected the globe and penetrated the orbital apex towards the middle cranial fossa to the point of touching but not penetrating the dura mater.

treatment is of utmost importance. Advances in radiologic imaging, alloplastic material development, surgical techniques and instruments, and studies of the natural course of posttraumatic sequelae continues to improve the surgeon's ability in this type of trauma management [22]. This report describes the first case of a patient with intra-orbital penetrating injury caused by a $9 \mathrm{~cm}$ bamboo stick. The stick passed through the lip and cheek to the orbit, deflecting the globe but not penetrating it and reaching the orbital foramen. We emphasize the importance of clinical results beyond the radiological findings which may not reveal the full impact of the injury. Unfortunately, despite careful and immaculate removal of the bamboo stick, the patient ended without light perception and with ophthalmoplegia.

\section{Case Report}

A 25-year-old man was admitted to the emergency room with multi trauma injuries after falling from a second-floor balcony into his neighbor's garden. On arrival, the patient was sedated and placed under artificial respiration. On physical examination, the only external evidence of injury was a $1.5 \mathrm{~cm}$ wooden foreign body protruding from the upper lip (Figure 1).
Closer examination revealed the foreign body inside the cheek without penetrating the oral cavity. Computed tomography (CT) of the head and face were performed. The images depicted a well formed, radiolucent area with a density similar to that of air in the right orbit. This was later identified as a foreign body penetrating the right orbit in an axial plane from inferior to superior direction. It deflected the globe and penetrated the orbital apex towards the middle cranial fossa to the point of touching but not penetrating the dura mater (Figure 2). A fracture in the floor of the right orbit without the involvement of the lower orbital rim was revealed (Figure 3). Herniation of the inferior Rectus muscle and fat from the orbit into the right maxillary sinus cavity were present (Figure 4). Ocular examination showed no injuries to the globe. The patient received tetanus toxoid and prophylactic intravenous wide spectrum antibiotics. The patient underwent an emergency operation, in the presence of an ophthalmologist and a neurosurgeon. The approach was extra-oral with the aim of exploring and removing the foreign body. The intra-orbital foreign body proved to be a $9 \mathrm{~cm}$ bamboo stick (Figure 5). The bamboo stick was meticulously removed. There 


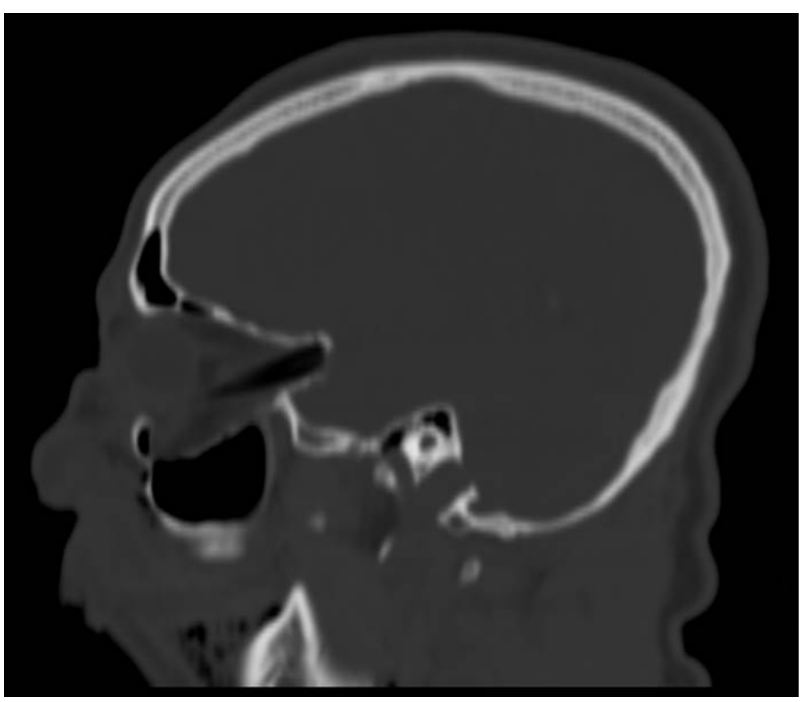

Figure 3: A fracture in the floor of the right orbit.

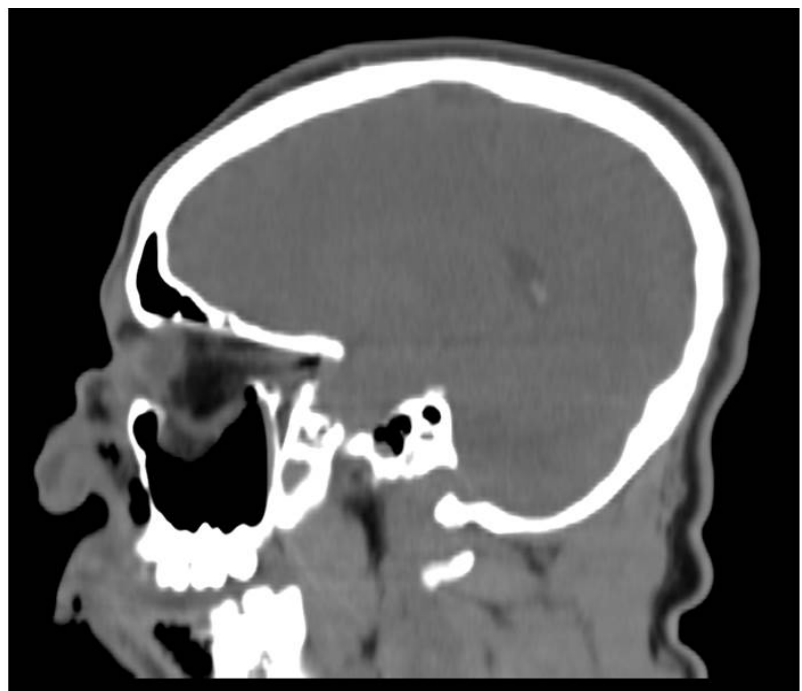

Figure 4: Herniation of the inferior Rectus muscle and fat from the orbit into the right maxillary sinus.

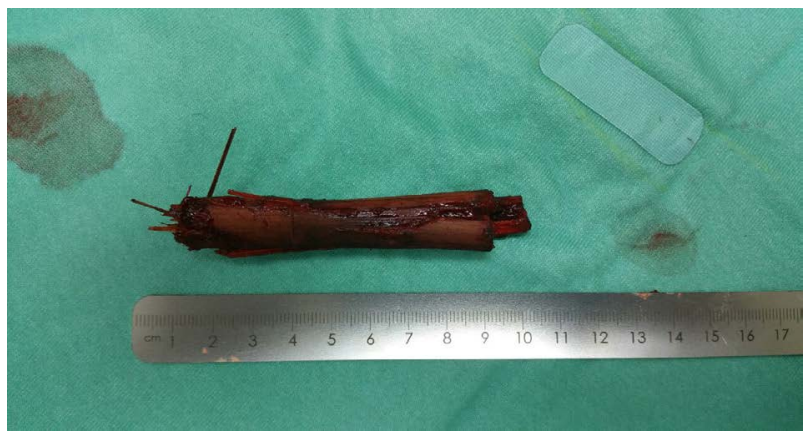

Figure 5: The intra-orbital foreign body proved to be a 9 $\mathrm{cm}$ bamboo stick.

was no leakage of cerebrospinal fluid (CSF) and no brain tissue was found during exploration examination of the foreign body after its removal. Immediate postoperatively, the patient was transferred to the intensive care. Follow up CT scan demonstrated intact right globe, optic nerve and dura mater. There were no radiolucent findings suggesting that no foreign body remnants were present.

\section{Discussion}

Various foreign bodies in the orbit have been described in the literature, such as door keys, nails, pencils, spectacle arms, metal bars, cotton buds, bicycle brake handles, plastic chopsticks, wooden foreign bodies, stones and even toilet brush handles [2233]. The entry wounds may be small due to elongated shapes or sharp ends of these objects. Due to the conical shape of the orbit and thinness of the orbital wall on the medial side, orbital foreign bodies can gain access into the intracranial cavity through the superior orbital fissure or optic canal and can lead to blindness and even death [34,35]. A high index of suspicion is essential for any eyelid or conjunctival laceration, particularly if orbital fat is visible. These indicate that the orbital septum has been breached [7]. Signs and symptoms depend on the nature of the foreign body, the degree of penetration and injury to the anatomical structures. In the case of plant material, its porous organic nature and its frequent proximity to soil make it a source of bacterial and fungal contamination [15]. It often causes inflammatory reactions because of infections thus making signs and symptoms more noticeable. Organic material may also break down into many pieces. The diagnostic methods used in such patients are plain radiography, ultrasonography (US), CT and magnetic resonance imaging (MRI). Plain radiography and 3-dimensional CT are excellent for detecting and localizing high-density foreign bodies in an emergency situation. However, organic materials such as wood are not well detected by plain radiography since these materials may be both radio- and sonolucent, and therefore indistinguishable from soft tissue or air in the orbit or cranial cavity. A wide variation in radiodensity may occur in a single piece of wood thus MRI is the better option in those cases $[15,21,36]$. A linear configuration should raise suspicion. As far as visual prognosis and status of neurovascular structures are concerned, it is related more to the direct impact from foreign body rather than surgical approaches [8]. In our patient, the foreign body which was radiolucent, was predicted to be a $9 \mathrm{~cm}$ object of organic origin. High-density 3-dimensional CT examination provided excellent images of the linear configuration mimicking air. Objectives of treatment in such patients are the surgical removal of the foreign body, the control of hemorrhage, and the repair of damage. Broad-spectrum antibiotic prophylaxis and tetanus immunization must be initiated immediately. Focal neurological signs should be monitored. Two major surgical approaches to orbitocranial foreign bodies can be used, depending on the location: transorbital and extraorbital (such as transcranial). There is always a risk of severe bleeding and death 
following the removal of a foreign body through the anterior approach due to the sudden release of the tamponading effect caused by the foreign body over the lacerated vessels [37]. In our patient, the foreign body did not penetrate the globe but penetrated the optic foramen. There were no indications of a potential intracranial injury. We decided to remove the bamboo stick by the extraorbital approach, pulling the stick out of the orbit through the entry port of the cheek. A neurosurgeon and an ophthalmologist were present in the operating theater, in case of emergency. The foreign body was removed in one piece without causing hemorrhage. Fragmented foreign body, if incompletely removed may cause abscess, granuloma or fistula.

\section{Conclusion}

We report an intra-orbital $9 \mathrm{~cm}$ bamboo stick penetrating injury. To the best of our knowledge this is the first such case reported in the literature. It is unusual in that there were no symptoms or signs to indicate an orbital penetrating injury despite the presence of the foreign body in the orbit. This report illustrates both the need for thorough examination and a strong index of suspicion even when the initial CT scan indicates the absence of a foreign body since radiologically, wood can masquerade as air.

\section{Highlights}

a. High index of suspicion for orbital penetrating injury is essential for any eyelid or conjunctival laceration, particularly if orbital fat is visible.

b. The porous organic nature of plant material and its frequent proximity to soil make it a source of bacterial and fungal contamination.

c. Organic materials such as wood are not well detected by plain radiography since these materials may be both radio- and sonolucent, and therefore indistinguishable from soft tissue or air in the orbit or cranial cavity.

d. A linear configuration should raise suspicion to the presence of orbital organic material..

\section{Declarations of Interest}

None.

\section{Acknowledgement}

All authors have equal contribution.

\section{References}

1. Nasr AM, Haik BG, Fleming JC, Al-Hussain HM, Karcioglu ZA (1999) Penetrating orbital injury with organic foreign bodies. Ophthalmology 106: 523-532.

2. Wesley RE, Anderson SR, Weiss MR, Smith HP (1987) Management of orbital cranial trauma. Adv Ophthalmic Plast Reconstr Surg 7: 3-26.

3. Fama F, Cicciu M, Sindoni A, Nastro-Siniscalchi E, Falzea
$\mathrm{R}$, et al. (2017) Maxillofacial and concomitant serious injuries: An eight-year single center experience. Chin $\mathrm{J}$ Traumatol 20: 4-8.

4. Satyarthee GD, Dawar P, Borkar SA, Sharma BS (2014) Trans-orbital penetrating head injury (TOPHI): Short series of two cases with review of literature. Indian J Neurotrauma 11: 49-52.

5. Liu WH, Chiang YH, Hsieh CT, Sun JM, Hsia CC (2011) Transorbital penetrating brain injury by branchlet: $\mathrm{A}$ rare case. J Emerg Med 41: 482-485.

6. Teymoorian S, San Filippo AN, Poulose AK, Lyon DB (2010) Perforating globe injury from Taser trauma. Ophthalmic Plast Reconstr Surg 26: 306-308.

7. Green BF, Kraft SP, Carter KD, Buncic JR, Nerad JA, et al. (1990) Intraorbital wood. Detection by magnetic resonance imaging. Ophthalmology 97: 608-611.

8. Finkelstein M, Legmann A, Rubin PA (1997) Projectile metallic foreign bodies in the orbit: $A$ retrospective study of epidemiologic factors, management, and outcomes. Ophthalmology 104: 96-103.

9. Matsuyama T, Okuchi K, Nogami K, Hata M, Murao Y (2001) Transorbital penetrating injury by a chopstick--case report. Neurol Med Chir (Tokyo) 41: 345-348.

10. Fama F, Cicciu M, Nastro-Siniscalchi E, Falzea R, Fodale $V$, et al. (2016) Nonfatal cervical-neck lesion with a wooden foreign body: Diagnosis and management. J Craniofac Surg 27: 175-176.

11. Roberts CF, Leehey PJ (1992) Intraorbital wood foreign body mimicking air at CT. Radiology $185: 507-508$.

12. Mutlukan E, Fleck BW, Cullen JF, Whittle IR (1991) Case of penetrating orbitocranial injury caused by wood. $\mathrm{Br} J$ Ophthalmol 75: 374-376.

13. Weisman RA, Savino PJ, Schut L, Schatz NJ (1983) Computed tomography in penetrating wounds of the orbit with retained foreign bodies. Arch Otolaryngol 109: 265268.

14. Specht CS, Varga JH, Jalali MM, Edelstein JP (1992) Orbitocranial wooden foreign body diagnosed by magnetic resonance imaging. Dry wood can be isodense with air and orbital fat by computed tomography. Surv Ophthalmol 36: 341-344.

15. Hansen JE, Gudeman SK, Holgate RC, Saunders SA (1988) Penetrating intracranial wounds: Clinical limitations of computerized tomography. J Neurosurg 68: 752-756.

16. Charteris DG (1988) Posterior penetrating injury of the orbit with retained foreign body. $\mathrm{Br} \mathrm{J}$ Ophthalmol 72: 432-433.

17. Quayle AA (1986) The significance of small wounds of the eyelids. Br J Oral Maxillofac Surg 24: 17-21.

18. Manfredi SJ, Raji MR, Sprinkle PM, Weinstein GW, Minardi LM, et al. (1981) Computerized tomographic scan findings in facial fractures associated with blindness. Plast Reconstr Surg 68: 479-490.

19. Ey W (1981) Orbital involvement in frontobasal injuries. Laryngol Rhinol Otol 60: 162-167.

20. Park SJ, Chi M (2018) Transorbital penetrating intracranial injury by a battery. J Craniofac Surg 29: e61-e64.

21. Arslan M, Eseoglu M, Gudu BO, Demir I (2012) Transorbital orbitocranial penetrating injury caused by a metal bar. $\mathrm{J}$ Neurosci Rural Pract 3: 178-181.

22. Chang EL, Bernardino CB (2004) Update on orbital trauma. Curr Opin Ophthalmol 15: 411-415. 
23. Seex K, Koppel D, Fitzpatrick M, Pyott A (1997) Trans-orbital penetrating head injury with a door key. J Craniomaxillofac Surg 25: 353-355.

24. Shenoy SN, Raja A (2003) Unusual self-inflicted penetrating craniocerebral injury by a nail. Neurol India 51: 411-413.

25. Di Roio C, Jourdan C, Mottolese C, Convert J, Artru F (2000) Craniocerebral injury resulting from transorbital stick penetration in children. Childs Nerv Syst 16: 503-506.

26. Al-Anazi A, Al-Luwimi I, Nasser M (2003) Transorbital penetrating craniocerebral injury by a spectacle arm: Suicidal attempts. Br J Neurosurg 17: 368-369.

27. Lin $H$, Lee $H$, Cho $D$ (2007) Management of transorbital brain injury. J Chin Med Assoc 70: 36-38.

28. Yamashita T, Mikami T, Baba T, Minamida $Y$, Sugino T, et al. (2007) Transorbital intracranial penetrating injury from impaling on an earpick. J Neuroophthalmol 27: 48-49.

29. Gopalakrishnan MS, Indira Devi B (2007) Fatal penetrating orbitocerebral injury by bicycle brake handle. Ind $J$ Neurotrauma 4: 123-124.

30. Balasubramanian C, Kaliaperumal C, Jadun CK, Dias PS (2009) Transorbital intracranial penetrating injury-an anatomical classification. Surg Neurol 71: 238-240.
31. Satyarthee GD, Borkar SA, Tripathi AK, Sharma BS (2009) Transorbital penetrating cerebral injury with a ceramic stone: Report of an interesting case. Neurol India 57: 331333.

32. Farhadi MR, Becker M, Stippich C, Unterberq AW, Kiening $\mathrm{KL}$ (2009) Transorbital penetrating head injury by a toilet brush handle. Acta Neurochir 151: 685-687.

33. Chibbaro S, Tacconi L (2006) Orbito-cranial injuries caused by penetrating non-missile foreign bodies. Experience with eighteen patients. Acta Neurochir (Wien) 148: 937-942.

34. Turbin RE, Maxwell DN, Langer PD, Frohman LP, Hubbi B, et al. (2006) Patterns of transorbital intracranial injury: A review and comparison of occult and non-occult cases. Surv Ophthalmol 51: 449-460.

35. Lasky JB, Epley KD, Karesh JW (1997) Household objects as a cause of self-inflicted orbital apex syndrome. J Trauma 42: 555-558.

36. Kamble H, Diyora B, Kukreja S, Nayak N, Sharma A (2011) Transorbital craniocerebral penetrating injury with iron cutting metal blade. Ind J Neurotrauma 8: 119-121.

37. Abhishek S, Shahid IS, SamarendraNG (2018) Intraorbital foreign body with intracranial extension: A case series. Int Clin Neurosci J 5: 43-45. 